\title{
Stage I Nasal Cavity Cancer AJCC v6 and v7
}

National Cancer Institute

\section{Source}

National Cancer Institute. Stage I Nasal Cavity Cancer A/CC v6 and v7. NCI Thesaurus.

Code C6013.

Stage I includes: T1, N0, M0. T1:T umor restricted to any one subsite, with or without bony invasion. NO: No regional lymph node metastasis. MO: No distant metastasis. (AJCC 6th and 7th eds.) 